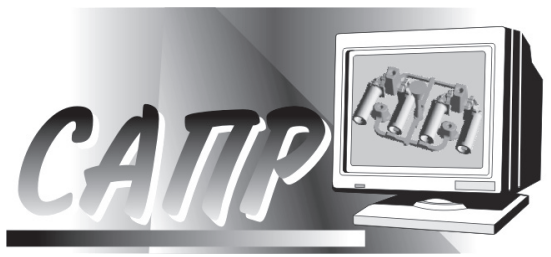

ПАРАМЕТРИЗАЦИЯ ИЗОБРАЖЕНИЙ МИКРОСТРУКТУР ЧУГУНА С ШАРОВИДНЫМ ГРАФИТОМ НА ОСНОВЕ ФУНКЦИИ ПЛОТНОСТИ РАСПРЕДЕЛЕНИЯ ГРАФИТА ПО РАЗМЕРАМ ВКЛЮЧЕНИЙ

\title{
PARAMETERIZATION OF MICROSTRUCTURES IMAGES OF SPHEROIDAL GRAPHITE CAST IRON ON THE BASIS OF THE GRAPHITE DISTRIBUTION DENSITY FUNCTION OF THE INCLUSIONS SIZE
}

\section{О. А. САЧЕК, А. Н. ЧИЧКО, С. Г. ЛИХОУЗОВ, Т. В. МАТЮШИНЕЦ, О. И. ЧИЧКО,}

Белорусский национальный технический университет, г. Минск, Беларусь, пр. Независимости, 65.

E-mail: osachok@mail.ru

O. A. SACHEK, A. N. CHICHKO, S. G. LIKHOUZOV, T. V. MATYUSHINETS, O. I. CHICHKO,

Belarusian National Technical University, Minsk, Belarus, 65, Nezavisimosti ave.E-mail: osachok@mail.ru

На основе микроструктур чугуна с различнылм диаметром включений шаровидного графита, приведенных в ГОСТ 3443-87, показаны возможности параметризаиии микроструктур типа ШГ2, ШГ4, ШГ6, ШГ10, ШГ12, Шгд15, Шәд25, Шгд45, Шгд90, Шгд180, Шгд360. Предложено для классификачии микроструктур чугуна с шаровидным графитом использовать функиию плотности распределения графита по размеру включений. Показано, что функиия плотности распределения графитовых включений может быть использована в качестве критерия классификации микроструктур чугуна с шаровидным графитом, что открывает новые возможности количественного анализа связей «микроструктура-свойства» для чугунов с шаровидным графитом.

The possibilities of parameterization of microstructures such as SHG2, SHG4, SHG6, SHG10, SHG12, SHgd15, SHgd25, SHgd45, SHgd90, SHgd180, SHgd360 according to GOST (State All-union standard) 3443-87 based on the microstructures of cast iron with different diameter spheroidal graphite are shown. It is proposed to use the function of the density distribution of graphite inclusions in size for the classification of cast iron microstructures with spheroidal graphite. It is shown that density function of graphite inclusions can be used as a criterion of classification of microstructures of cast iron with spheroidal graphite, that offers new opportunities for the quantitative analysis of relations «microstructure-property» for cast iron with spheroidal graphite.

Ключевые слова. Микроструктура, чугун, шаровидный графит, обработка изображений.

Keywords. Microstructure, cast iron, spheroidal graphite, image processing.

\section{Введение}

Математическое моделирование микроструктур сплавов с целью их параметризации является новым научным направлением, которое создано на стыке двух отраслей знаний - металловедения и информационных технологий в Белорусском национальном техническом университете на кафедре «Машины и технология литейного производства». Необходимость решения задач параметризации связана с развитием методов автоматизации и повышения уровня исследований связей «микроструктура - свойства». Современный уровень развития металловедения для решения задач по установлению взаимосвязей между параметрами микроструктуры и свойствами сплавов до сих пор остается на низком уровне. Например, нет математических зависимостей между пределом прочности, твердостью и параметрами микроструктуры, хотя известно, что механические свойства определяются именно структурными факторами, такими, как распределение фазовых составляющих и их соотношения в микроструктуре. Анализ особенностей строения фаз - это качественный анализ микроструктуры и, как показывает практика, он далеко не всегда является информативным для установления взаимосвязей между микроструктурой и свойствами сплава. 


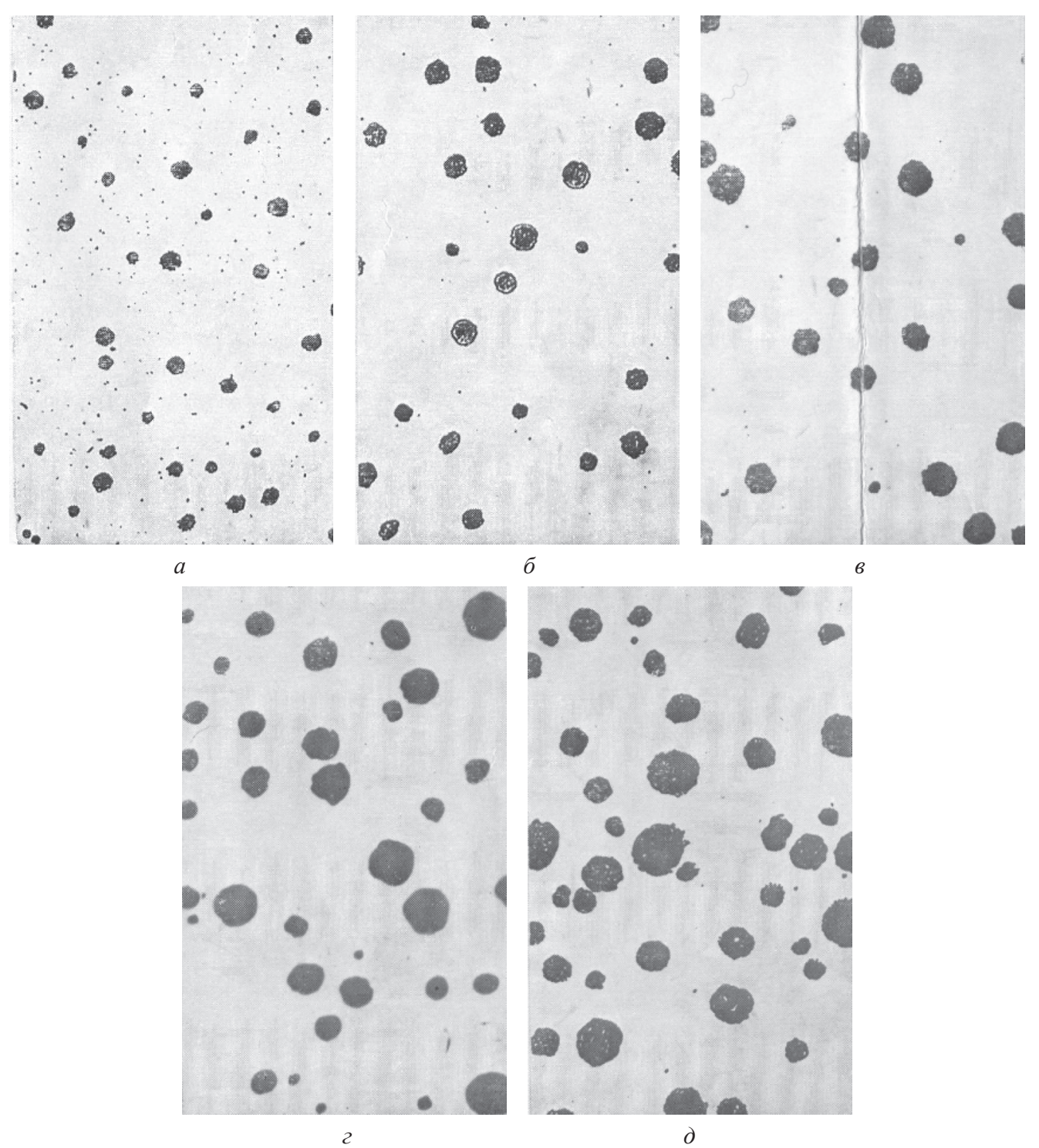

Рис. 1. Изображения микроструктур чугуна с шаровидным графитом ШГ2 (a), ШГ4 (б), ШГ6 (в), ШГ10 (2), ШГ12 (d), ГОСТ $3443-87$

Развитие компьютерных технологий открывает новые возможности для анализа микроструктур промышленных сплавов. В [1-5], посвященных обработке изображений микроструктур, было показано, что методы обработки изображений микроструктур позволяют с новых позиций анализировать процессы структурообразования в сплавах, что дает новый инструмент металловеду для исследования взаимосвязей «микроструктура-свойства сплава».

Цель настоящей работы - разработка метода параметризации микроструктур чугуна с шаровидным графитом с помощью функций плотности распределения графита по размерам его включений на основе оцифрованных изображений микроструктур, представленных в ГОСТ 3443-87 «Отливки из чугуна с различной формой графита. Методы определения структуры».

Настоящая работа является развитием исследований, выполненных по заданиям Государственной научной прикладной программы «Металлургия» НАН Беларуси.

\section{Исходные данные и алгоритм исследования микроструктур ШГ2, ШГ4, ШГ6, ШГ10, ШГ12, ГОСТ 3443-87}

В качестве исходных данных были использованы микроструктуры чугуна с шаровидным графитом. На рис. 1 представлены изображения микроструктур чугуна с различным количеством включений шаровидного графита ШГ2 (площадь, занятая графитом до 3\%), ШГ4 (от 3 до 5\%), ШГ6 (от 5 до 8\%), ШГ10 (от 8 до 12\%), ШГ12 (больше 12\%) согласно ГОСТ 3443-87.

Для обработки микроструктур был использован следующий компьютерный алгоритм, разработанный на основе методов, описанных в [1-5]. 

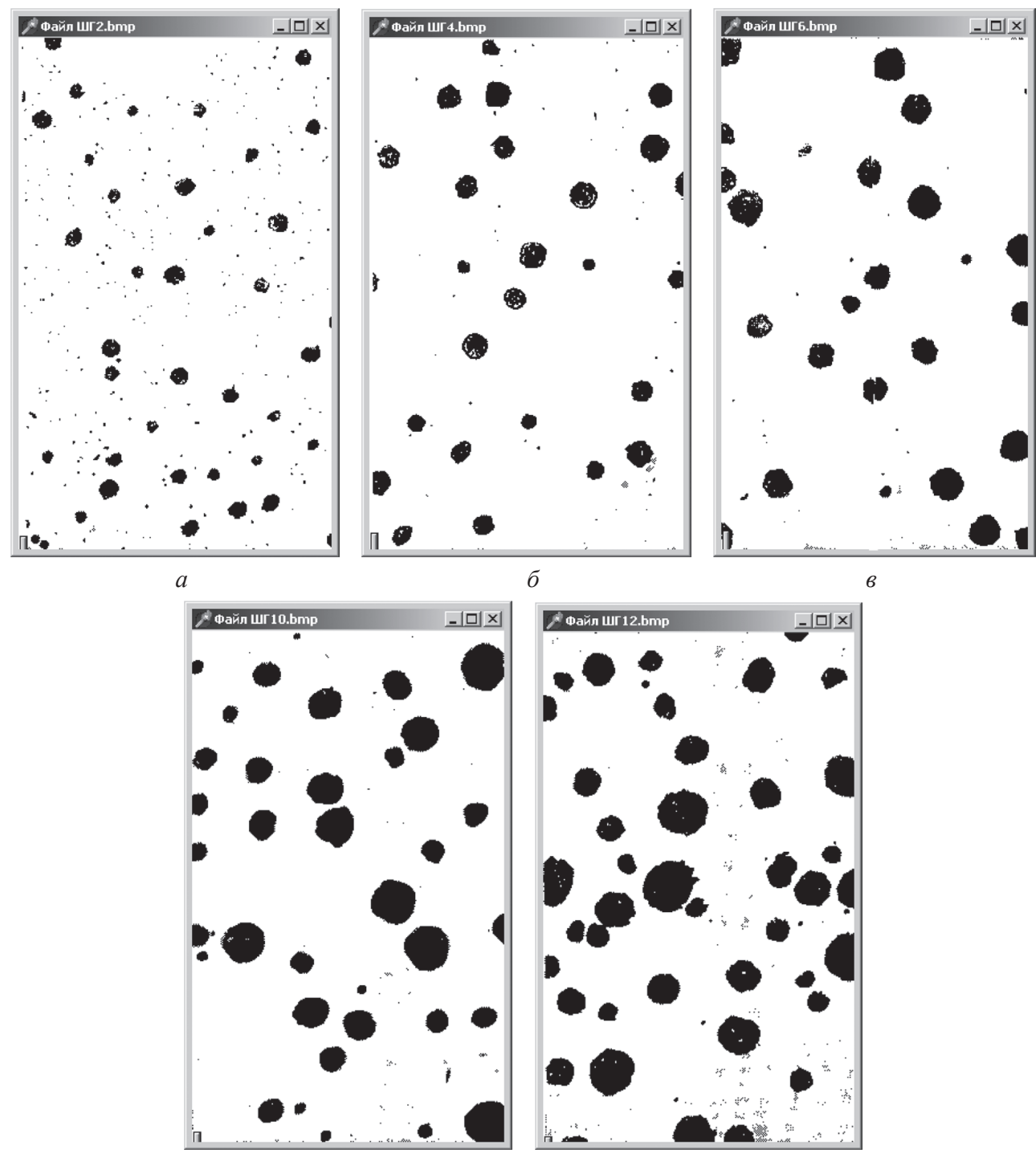

Рис. 2. Бинаризованные изображения микроструктур чугуна с шаровидным графитом ШГ2 (a), ШГ4 (б), ШГ6 (в), ШГ10 (2), ШГ12 (d)

Шаг 1. Сканирование изображения микроструктуры.

Шаг 2. Бинаризация изображения микроструктуры с различным пороговым значением.

Шаг 3. Математическая обработка изображений микроструктур с целью определения функции плотности распределения размеров графитных включений.

Шаг 4. Нормирование функций плотности распределения по результатам бинаризации для анализа микроструктур.

На рис. 2 показаны исходные бинаризованные микроструктуры (порог бинаризации 0,75) чугуна с шаровидным графитом, использованные для расчета плотности распределения графитных включений.

\section{Результаты параметризации микроструктур, ГОСТ 3443-87}

На рис. 3-6 представлены гистограммы функции плотности распределения включений шаровидного графита для микроструктур согласно ГОСТ 3443-87. Как видно из рисунков, для каждой пары структур с близкими баллами функция плотности распределения графита для структуры с большим баллом имеет тенденцию к смещению вправо по оси абсцисс, что говорит о возможности использования функции плотности распределения графита в качестве критерия оценки балльности структур чугуна по характеристике «Количество включений шаровидного графита».

Рассчитанные распределения показывают возможности параметризации микроструктур высокопрочных чугунов с помощью функции плотности распределения графитовых включений, что может быть использовано в заводских лабораториях для повышения точности микроструктурного анализа чу- 


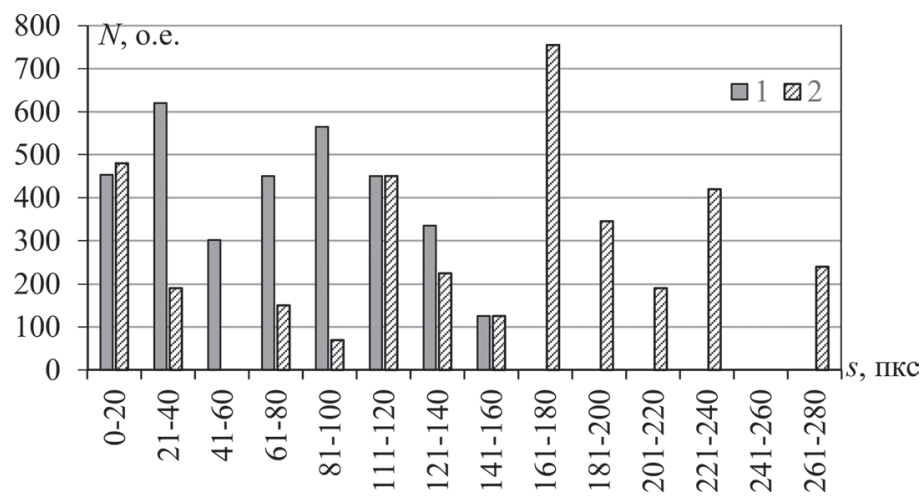

Рис. 3. Функции плотности распределения графита от размера включений, показывающие возможности количественной классификации промежуточных микроструктур, находящихся в интервале ШГ2 (1) и ШГ4 (2)

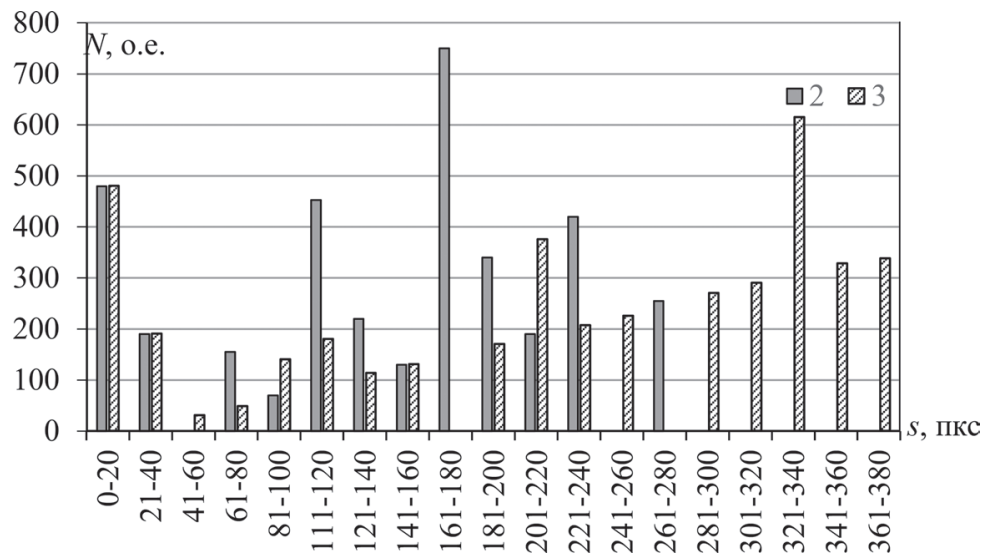

Рис. 4. Функции плотности распределения графита от размера включений, показывающие возможности количественной классификации промежуточных микроструктур, находящихся в интервале ШГ4 (2) и ШГ6 (3)

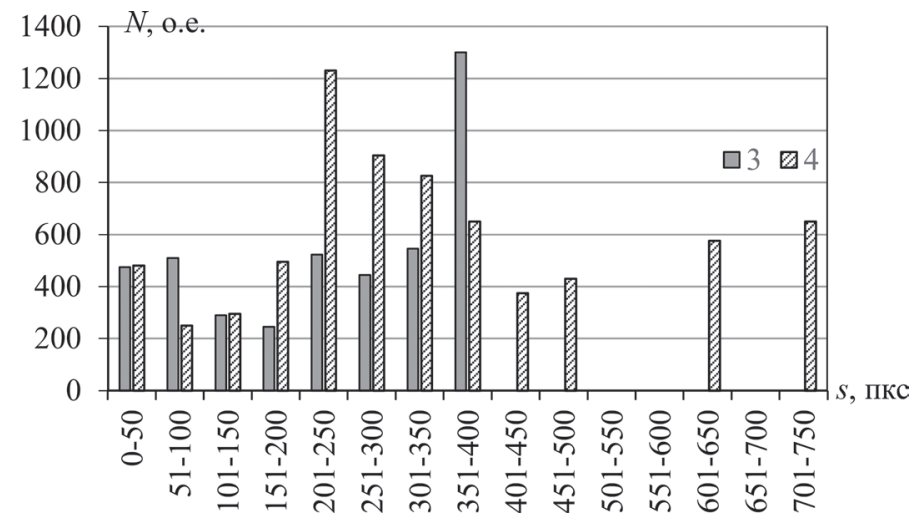

Рис. 5. Функции плотности распределения графита от размера включений, показывающие возможности количественной классификации промежуточных микроструктур, находящихся в интервале ШГ6 (3) и ШГ10 (4)

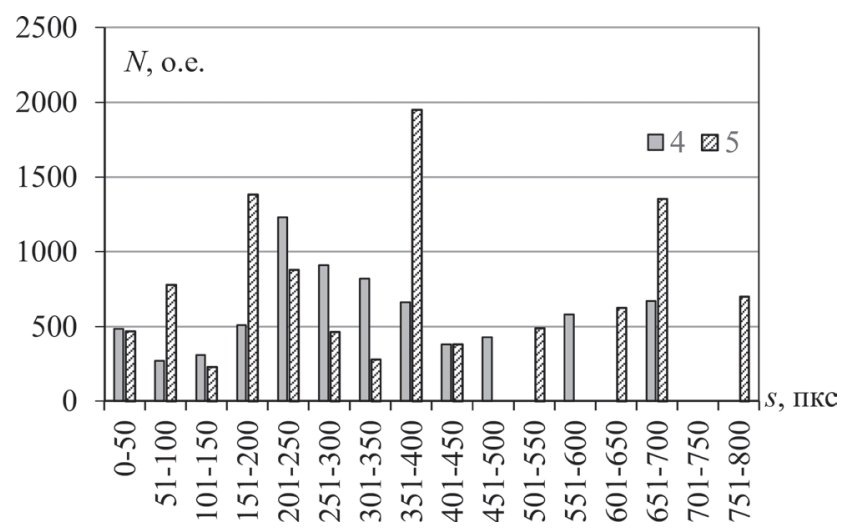

Рис. 6. Функции плотности распределения графита от размера включений, показывающие возможности количественной классификации промежуточных микроструктур, находящихся в интервале ШГ10 (4) и ШГ12 (5) 


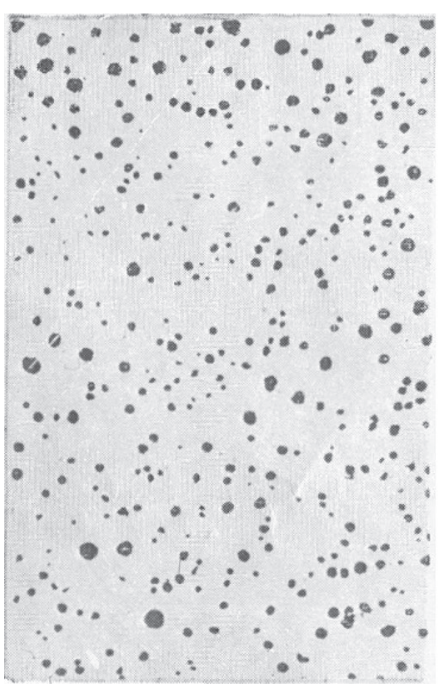

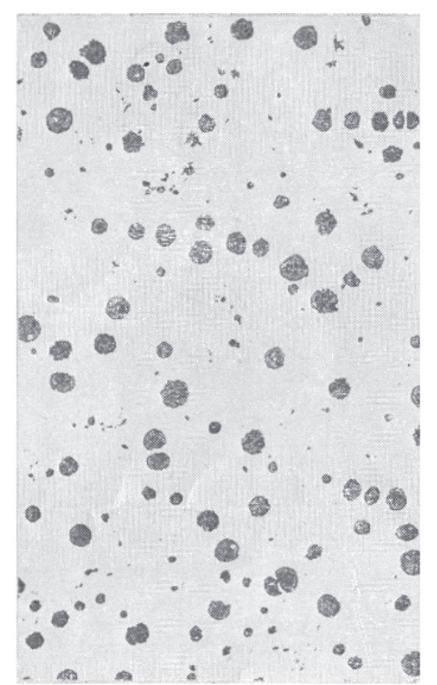

$\sigma$

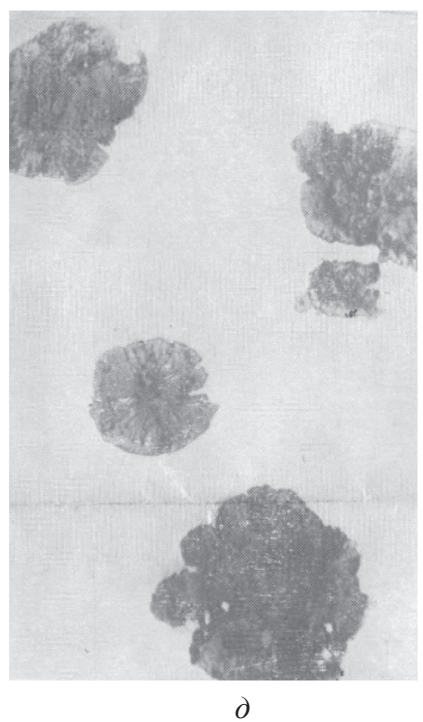

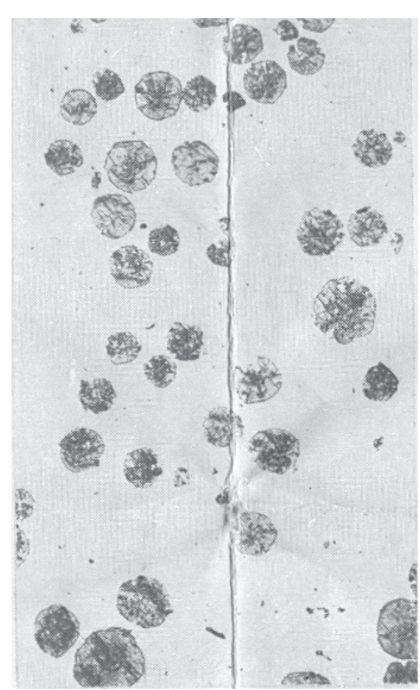

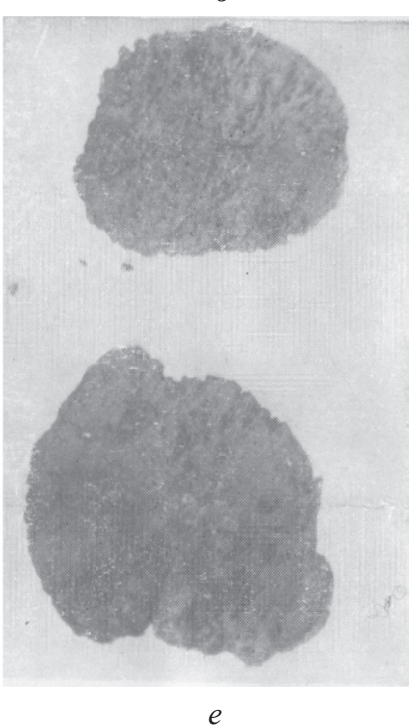

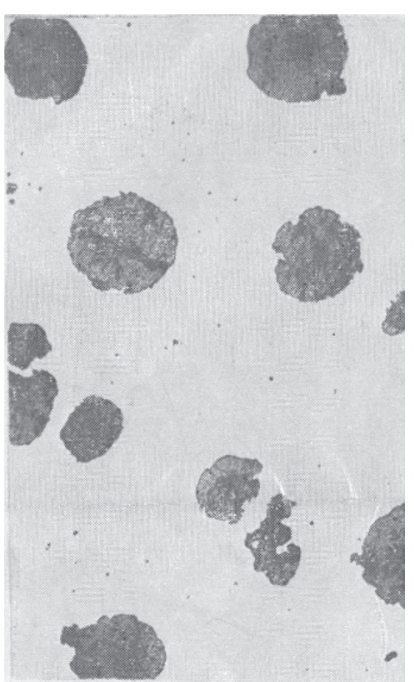

2

Рис. 7. Изображения микроструктур чугуна с шаровидным графитом, ГОСТ 3443-87, с различным диаметром включений графита ШГд15 (a); ШГд25 (б); ШГд45 (в); ШГд90 (2); ШГд180 (д); ШГд360 (e)

гунов за счет перехода от качественного анализа к количественным оценкам, что открывает новые возможности для исследования взаимосвязей «микроструктура - механические свойства чугуна».

\section{Результаты параметризации микроструктур ШГд15, ШГд25, ШГд45, ШГд90, ШГд180, ШГд360, ГОСТ 3443-87}

На рис. 7 представлены изображения микроструктур чугуна с различными размерами включений графита ШГд15 (диаметр включений до 15 мкм), ШГд25 (от 15 до 30 мкм), ШГд45 (от 30 до 60 мкм), ШГд90 (от 60 до 120 мкм), ШГд180 (от 120 до 250 мкм), ШГд360 (от 250 до 500 мкм) согласно ГОСТ 3443-87. На рис. 8 показаны бинаризованные с порогом 0,75 микроструктуры ШГд15, ШГд25, ШГд45, ШГд90, ШГд180, ШГд360.

На рис. 9-12 представлены гистограммы для сравнения распределений диаметров шаровидных графитовых включений различной величины для микроструктур ГОСТ 3443-87. Как видно из рис. 9, расчетные функции плотности распределения по диаметрам графитной фазы для микроструктур ШГд15 и ШГд25 существенно различаются. В частности, для структуры ШГд25 функция плотности распределения графитных включений смещена в сторону больших размеров графита. Аналогичная ситуация наблюдается при сравнительном анализе функций распределения для микроструктур ШГд25 и ШГд45 (рис.10), ШГд45 и ШГд90 (рис.11), ШГд90 и ШГд180 (рис. 12).

Каждая пара микроструктур с близкими баллами может быть легко классифицирована и вычислена с помощью критериев функции плотности распределения графитовых включений, что говорит о воз- 

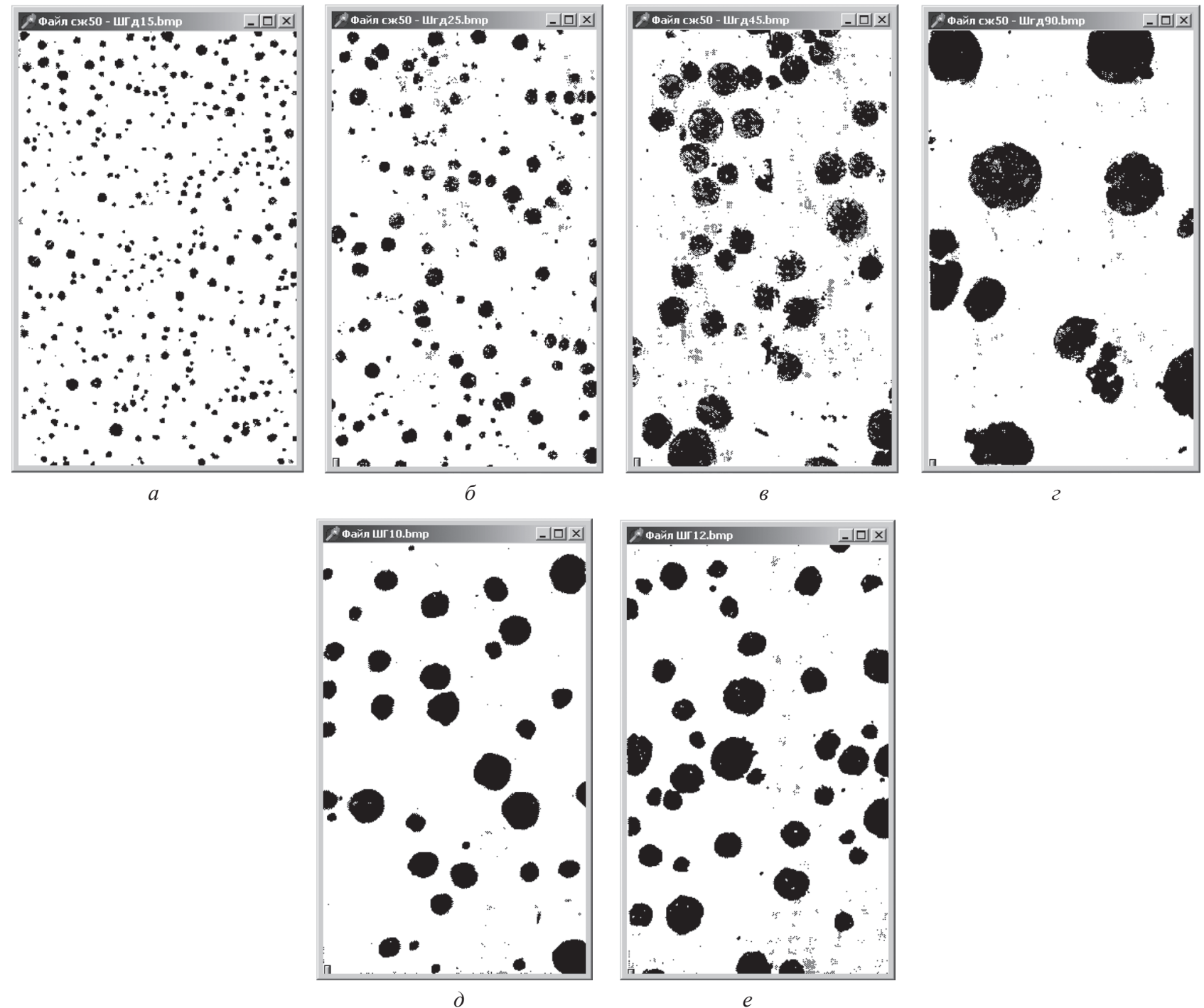

Рис. 8. Бинаризованные изображения микроструктур чугуна с шаровидным графитом, ГОСТ 3443-87, с различным диаметром включений графита ШГд15 (a); ШГд25 (б); ШГд45 (в); ШГд90 (2); ШГд180 (д); ШГд360 (e)

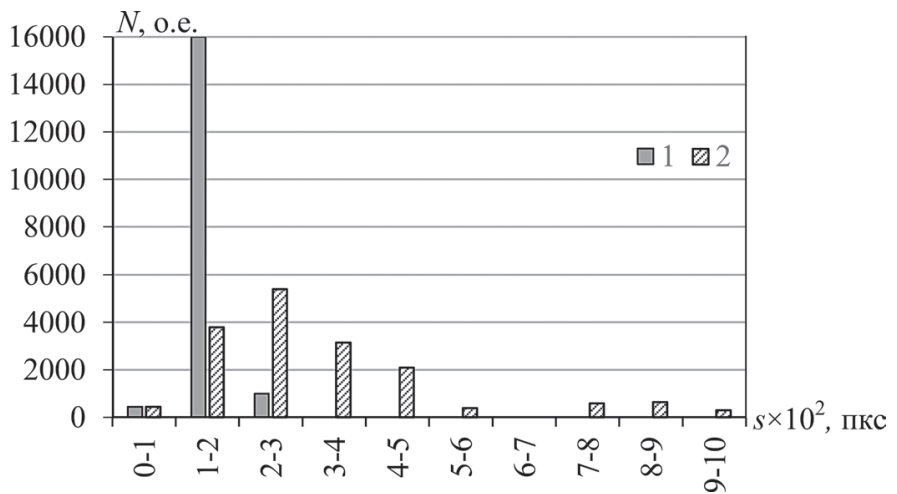

Рис. 9. Функции плотности распределения графита от размера включений, показывающие возможности количественной классификации промежуточных микроструктур, находящихся в интервале ШГд15 (1) и ШГд25 (2)

можности использования функции распределения графита в качестве критерия оценки балльности структур чугуна с шаровидным графитом.

Для простейшего примера можно использовать величины $P_{1}$ и $P_{2}$, характеризующие максимальный и средний диаметры включений графита как рассчитанные количественные характеристики функции плотности распределения графитной фазы.

Параметры $P_{1}$ и $P_{2}$ определяли по следующим формулам: 


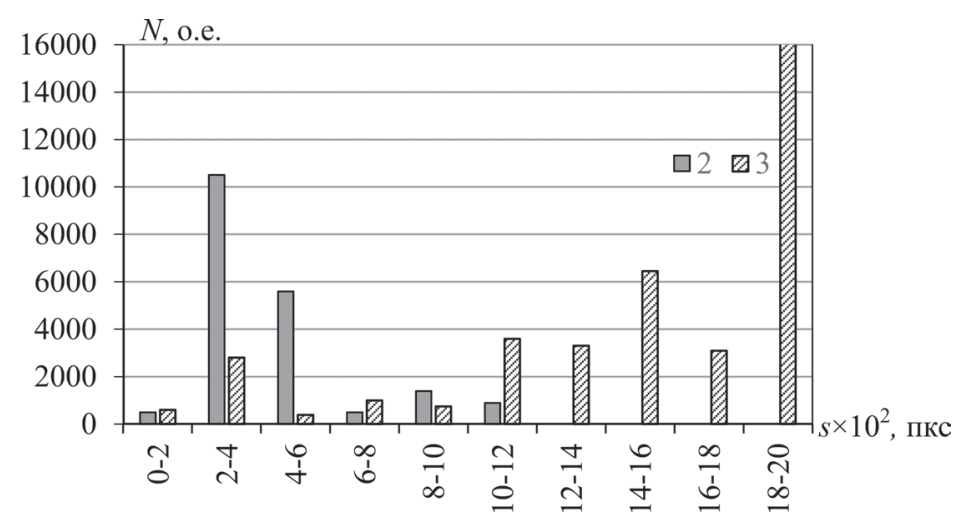

Рис. 10. Функции плотности распределения графита от размера включений, показывающие возможности количественной классификации промежуточных микроструктур, находящихся в интервале ШГд25 (2) и ШГд45 (3)

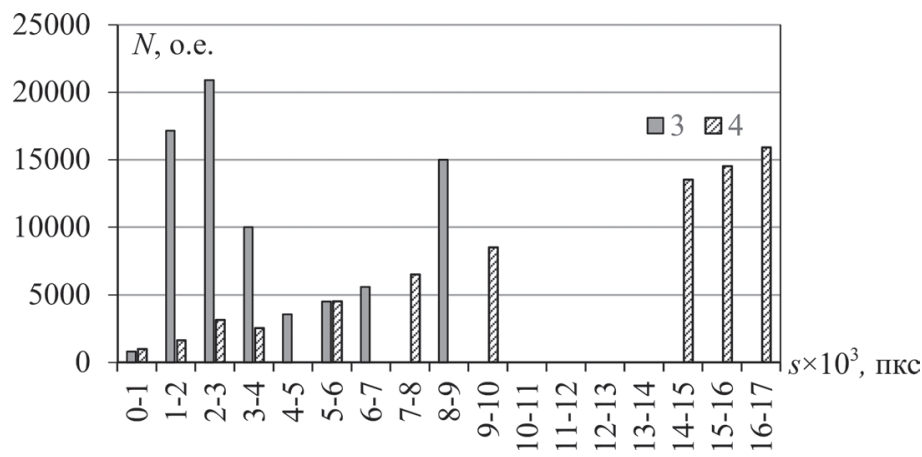

Рис. 11. Функции плотности распределения графита от размера включений, показывающие возможности количественной классификации промежуточных микроструктур, находящихся в интервале ШГд45 (3) и ШГд90 (4)

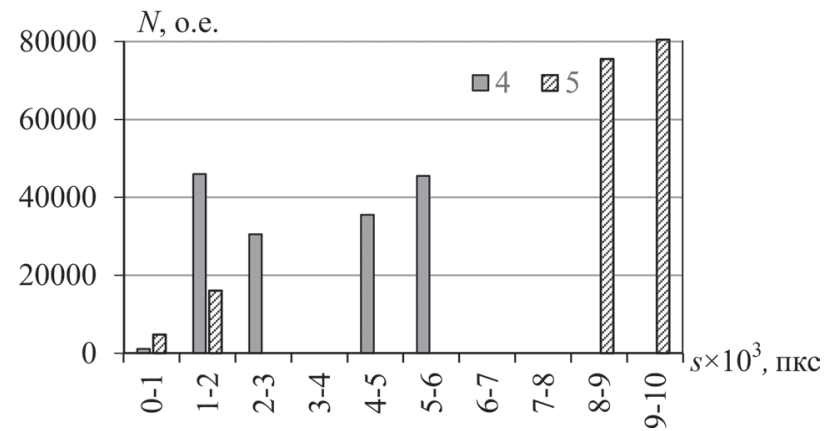

Рис. 12. Функции плотности распределения графита от размера включений, показывающие возможности количественной классификации промежуточных микроструктур, находящихся в интервале ШГд90 (4) и ШГд180 (5)

$$
\begin{gathered}
P_{1}=\frac{\sum_{k=m}^{q} d_{k}}{q-m+1}, \\
P_{2}=\sum_{k=1}^{q} F_{d}\left(d_{k}\right) d_{k},
\end{gathered}
$$

где $F_{d}\left(d_{k}\right)$ - нормированная функция распределения диаметров включений микроструктуры для $q$ интервалов дискретизации; $d_{k}=\Delta d k, k=1, q$ - дискретные значения диаметров включений функции $F_{d}\left(d_{k}\right)$; $\Delta d$ - шаг дискретизации диаметров включений; $m$ - интервал дискретизации, для которого выполняется условие $t_{m-1} \Delta d<0,9 \sum_{k=1}^{q} F_{d}\left(d_{k}\right) d_{k} \leq t_{m} \Delta d, m<q$.

На рис. 13, 14 представлены графики зависимости значений критериев $P_{1}$ и $P_{2}$ от микроструктур ШГд15; ШГд25; ШГд45; ШГд90; ШГд180; ШГд360. Как видно из рисунков, существует четкая корреляция между балльностью графитной фазы в чугуне с шаровидным графитом и изменением значений количественных критериев функции плотности $P_{1}$ и $P_{2}$. Это свидетельствует о возможности применения 


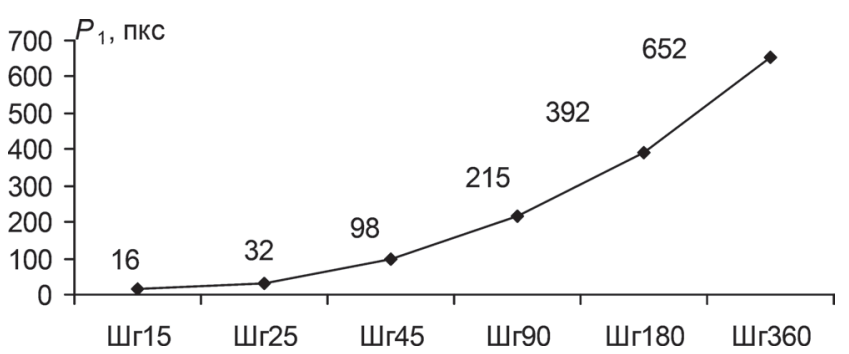

Рис. 13. Рассчитанная зависимость значений критерия $P_{1}$ от типа микроструктуры чугунов с различным размером включений графитной фазы

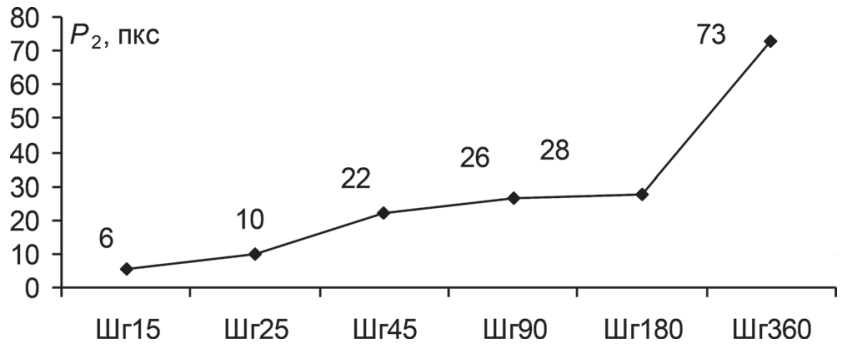

Рис. 14. Рассчитанная зависимость значений критерия $P_{2}$ от типа микроструктуры чугунов с различным размером включений графитной фазы

критериев $P_{1}$ и $P_{2}$ для единой комплексной автоматизированной оценки микроструктуры с присвоением ей необходимого балла по характеристике «Диаметр шаровидного графита».

Полученные закономерности (рис. 13,14 ) позволяют сделать вывод о количественной взаимосвязи между параметрами изображений микроструктур чугуна с шаровидным графитом, представленными в ГОСТ 3443-87, и критериями функции плотности распределения графитовых включений.

Таким образом, микроструктуры ШГд15, ШГд25 и ШГд45, ШГд90, ШГд180 и ШГд360 могут быть параметризованы с помощью функций плотности распределения графитовых включений, что может быть использовано для разработки методов автоматизации в задачах оценки классификации свойств чугуна с шаровидным графитом.

\section{Выводы}

На основе микроструктур чугуна с различным размером включений шаровидного графита, приведенных в ГОСТ 3443-87 «Отливки из чугуна с различной формой графита. Методы определения структуры», показаны возможности параметризации (функция плотности распределения) микроструктур ШГ2, ШГ4, ШГ6, ШГ10, ШГ12, Шгд15, Шгд25, Шгд45, Шгд90, Шгд180, Шгд360 на основе методов цифровой обработки изображений, что позволяет разработать методики для перехода от качественной шкалы микроструктур, используемой для анализа графитной фазы, к количественной.

Предложенный подход может быть использован для создания методов автоматизированной обработки микроструктур чугуна с шаровидным графитом с целью повышения точности и производительности работ в заводских лабораториях.

\section{Литература}

1. Лихоузов С. Г. О методах компьютерной обработки микроструктур сталей с различной дисперсностью перлита / С. Г. Лихоузов, О. А. Сачек, А. Н. Чичко // Информатика и системы управления. 2010. № 1. С. 19-29.

2. Чичко А. Н. О методах математического описания изображений микроструктур перлитных сталей/ А. Н. Чичко, О. А. Сачек // Вест. Полоц. гос. ун-та. Сер. С. Фундаментальные науки. 2010. № 3. С. 15-22.

3. Чичко А. Н. Программное обеспечение и алгоритмы для анализа изображений микроструктур перлитных сталей / А. Н. Чичко, О. А. Сачек, С. Г. Лихоузов // Программные продукты и системы. 2010. № 4. С. 123-127.

4. Чичко А. Н. Методы автоматизации обработки изображений микроструктур перлитных сталей / А. Н. Чичко, О. А. Сачек, С. Г. Лихоузов // Информационные технологии. 2010. № 7. С. 71-77.

5. Чичко А. Н. Компьютерная обработка изображений микроструктур серых чугунов как инструмент количественного анализа распределения графита / А. Н. Чичко, О. А. Сачек, С. Г. Лихоузов, О. И. Чичко // Литье и металлургия. 2013. № 2. С. $62-67$.

\section{References}

1. Lihouzov S. G., Sachek O. A., Chichko A. N. O metodah komp'yuternoy obrabotki mikrostruktur staley s razlichnoy dispersnost'yu perlita [About methods the computer processing of steel microstructures with different dispersability of perlite]. Informatika i sistemy upravleniya $=$ Informatics and control systems, 2010, no. 1, pp. 19-29. 
2. Chichko A. N., Sachek O. A. O metodah matematicheskogo opisaniya izobrazheniy mikrostruktur perlitnyh staley [About methods of mathematical description of the image of the microstructure of pearlite steels]. Vestnik Polotskogo gosudarstvennogo universiteta. Seriya C. Fundamental'nye nauki = Herald of Polotsk State University. Series C. The Fundamental Sciences, 2010, no. 3, pp. $15-22$.

3. Chichko A. N., Sachek O. A., Lihouzov S. G. Programmnoe obespechenie i algoritmy dlya analiza izobrazheniy mikrostruktur perlitnyh staley [Software and algorithms for the analysis of microstructures images pearlite steels]. Programmnye produkty $i$ sistemy $=$ Software products and systems, 2010, no. 4, pp. 123-127.

4. Chichko A. N., Sachek O. A., Lihouzov S. G. Metody avtomatizatsii obrabotki izobrazheniy mikrostruktur perlitnyh staley [Automated methods for image processing microstructures of pearlite steels]. Informatsionnye tehnologii = Information technologies, 2010, no. 7, pp. 71-77.

5. Chichko A. N., Sachek O. A., Lihouzov S. G., Chichko O. I. Komp'yuternaya obrabotka izobrazheniy mikrostruktur seryh chugunov kak instrument kolichestvennogo analiza raspredeleniya grafita [Computer imag processing of microstructures of gray cast iron as a tool for quantitative analysis of graphite distribution]. Lit'e $i$ metallurgiya $=$ Foundry production and metallurgy, 2013, no. 2, pp. 62-67. 